\title{
Diversidade genética entre cultivares de mangueiras, baseada em caracteres de qualidade dos frutos
}

\author{
Danielle Fabíola Pereira da Silva ${ }^{*}$, Dalmo Lopes de Siqueira ${ }^{2}$, Aline Rocha ${ }^{3}$, Luiz Carlos Chamhum Salomão², \\ Rosana Gonçalves Pires Matias ${ }^{4}$, Tiago Barbosa Struiving ${ }^{5}$
}

\section{RESUMO}

A mangueira é uma das fruteiras mais importantes do Brasil. Apesar de existirem muitos cultivares, o cultivo tem sido realizado basicamente com o cultivar 'Tommy Atkins' e existem poucos trabalhos sobre caracterização e análise da diversidade genética dos genótipos disponíveis. Por isso, o objetivo deste trabalho foi estudar a diversidade genética de 15 cultivares de mangueiras, produzidos na Zona da Mata Mineira, sendo oito brasileiros e sete oriundos da Flórida (EUA). Para isto, frutos maduros dos 15 cultivares foram colhidos e analisados química e fisicamente. Os cultivares que se apresentaram mais similares foram 'Kent' e 'Palmer'. O cultivar 'Extrema' não se agrupou com os outros pelo método de agrupamento UPGMA, e, por esta análise houve a separação dos cultivares brasileiros e norte-americanos. Quanto às características químicas, a técnica de componentes principais não agrupou os cultivares 'Extrema' e 'Tommy Atkins' com os demais; já quanto às características físicas, observou-se a mesma separação obtida pelo agrupamento UPGMA, com exceção do cultivar 'Extrema' que, neste caso, agrupou-se com os demais cultivares. Observou-se correlação entre a coloração da polpa, o ângulo hue e o teor de açúcares solúveis totais e entre a coloração da casca, o índice b* e a percentagem de casca e polpa.

Palavras-chave: Mangifera indica L., correlação, agrupamento.

\section{ABSTRACT}

\section{Genetic diversity among cultivars of mango based on fruit quality traits}

The mango crop is one of the most significant agribusiness in Brazil. Although there are many cultivars, cultivation has been done primarily with 'Tommy Atkins' and there are few studies on characterization and analysis of genetic diversity in different areas of production. Therefore, the objective of this work was to study the genetic diversity of fifteen mango cultivars, eight from Brazil and seven from Florida (USA), produced in the Zona da Mata Mineira region. Fifteen ripe fruits from each cultivar were collected and analyzed chemically and physically. The cultivars that showed more similarities were 'Kent' and 'Palmer'. 'Extrema' was not grouped with the others by the UPGMA clustering method. This analysis was also used for the separation of Brazilian and USA cultivars. The principal component analysis of the chemical characteristics did not group the cultivars 'Extrema' and 'Tommy Atkins' with the others. The physical characteristics showed the same separation obtained by the UPGMA method, except for the cultivar 'Extrema' that was grouped with other cultivars. There was correlation between the color of the pulp, hue angle, and total soluble sugar content and between the color of the peel, b* index and percentage of peel and pulp.

Key words: Mangifera indica L., correlation, clusters.

Recebido para publicação em 25/02/2011 e aprovado em 19/12/2011

${ }^{1}$ Engenheira-Agrônoma, Doutora. Pós-Doutoranda do Departamento de Fitotecnia, Universidade Federal de Viçosa, Av. Peter Henry Rolfs s/n., 36570-000, Viçosa, Minas Gerais, Brasil.danieele@ufv.br (*Autora correspondente.)

${ }^{2}$ Engenheiros-Agrônomos, Doutores. Departamento de Fitotecnia, Universidade Federal de Viçosa, Av. Peter Henry Rolfs s/n., 36570-000, Viçosa, Minas Gerais, Brasil. Isalomao@ufv.br; siqueira@ufv.br

${ }^{3}$ Engenheira-Agrônoma, Doutora. Instituto Federal de Educação, Ciência e Tecnologia do Sertão Pernambucano, Rodovia BR 235, Km 22, 56300-000, Petrolina, Pernambuco, Brasil. rochaline@ hotmail.com

${ }^{4}$ Engenheira-Agrônoma, Mestre. Doutoranda do Departamento de Fitotecnia, Universidade Federal de Viçosa, Av. Peter Henry Rolfs s/n., 36570-000, Viçosa, Minas Gerais, Brasil. rosana.pires@ufv.br

${ }^{5}$ Graduando em Agronomia. Departamento de Fitotecnia, Universidade Federal de Viçosa, Av. Peter Henry Rolfs s/n, 36570-000, Viçosa, Minas Gerais, Brasil. struiving @ hotmail.com 


\section{INTRODUÇÃO}

A divergência genética é um dos mais importantes parâmetros avaliados por melhoristas de plantas na fase inicial de um programa de melhoramento genético. Muitos métodos estão disponíveis para avaliá-la em populações de plantas, diferenciando-se na habilidade em detectar diferenças entre genótipos, custos, facilidade de uso, consistência e repetibilidade dos resultados (Morales et al., 2011). Essa quantificação da diversidade genética pode ser realizada por meio de caracteres agronômicos, morfológicos e moleculares, entre outros (Amorim et al., 2007).

As técnicas de análise multivariada podem ser utilizadas para avaliar a divergência entre acessos e para selecionar os descritores mais importantes, na discriminação dos acessos de um banco de germoplasma (Rodrigues et al., 2010). Entre as técnicas estatísticas multivariadas, destacam-se a análise de componentes principais e os métodos de agrupamento (Cruz, 2006).

Nos métodos de agrupamento não se conhece, a priori, o número de grupos a serem estabelecidos e diferentes métodos proporcionam diferentes resultados. A análise de componentes principais é um método que permite transformar um conjunto de variáveis iniciais, correlacionadas entre si, num outro conjunto de variáveis não correlacionadas, que resultam em combinações lineares ortogonais, e é utilizada com o objetivo da redução do espaço paramétrico (Rodrigues et al., 2010).

A análise de agrupamento trata da identificação de grupos de indivíduos similares, após a estimação de uma matriz de dissimilaridade. Há vários métodos de agrupamento, que se diferenciam pelo tipo de resultado e pelas diferentes formas de definir a proximidade entre indivíduos ou grupos formados. Em todos os casos, não se conhece, a priori, o número de grupos a serem estabelecidos e diferentes métodos proporcionam diferentes resultados (Rodrigues et al., 2010).

No entanto, é importante que sejam selecionados os caracteres adequados, como relatam Chahidi et al. (2008), que demonstraram ser ineficiente o uso de caracteres relacionados com a planta e a folha, no estudo de divergência genética da tangerina (Citrus reticulata), sendo os caracteres de fruto mais informativos e úteis nesse caso.

Nas várias regiões de cultivo de manga, tentativas de cruzamentos estão sempre em andamento para a criação de melhores cultivares. Informações sobre as relações genéticas dentro de tal diversidade do germoplasma são necessárias para a realização de programas de melhoramento eficientes (Pandit et al., 2007).

Entre as características que podem servir de suporte para a avaliação da qualidade de mangas estão a aparência externa, o sabor, o odor, o teor de fibras, a textura, o valor nutritivo, o tamanho, a massa e a forma dos frutos. Essas características poderão variar muito, conforme a variedade e o local de cultivo, além de ocorrerem alterações sensíveis durante o processo de amadurecimento (Silva et al., 2009).

A caracterização possibilita o estudo de diversidade genética entre acessos ou populações, permitindo a identificação de possíveis genitores, ou, até mesmo, de genótipos com características superiores. Quando um material com qualidade superior é identificado, no caso de espécies frutíferas como a mangueira, que é propagada vegetativamente, sua multiplicação torna-se facilitada. Para Moura et al. (1999), a determinação da dissimilaridade genética, por meio da avaliação simultânea de vários caracteres, pode ser uma ferramenta eficiente para a identificação de genótipos superiores.

Galli et al. (2008) avaliaram a qualidade dos frutos de 39 cultivares de manga, produzidos em São Paulo, e concluíram que o cultivar "Smith" destacou-se pelos frutos com maior massa total (694 g), maior percentagem de polpa $(85,7 \%)$, menor percentagem de caroço $(6,3 \%)$ e maior teor de $\operatorname{SST}\left(24,9^{\circ}\right.$ Brix).

Na Zona da Mata Mineira, o cultivar de mangueira mais produzido é o 'Ubá'; porém, existem outros cultivares em produção nesta região, o que tem gerado procura por informações não somente sobre as formas de cultivo, mas, também, sobre a qualidade dos frutos produzidos.

Para diversas fruteiras, a distinção entre cultivares pode ser realizada com base em características dos frutos e das folhas, permitindo a diferenciação dessas plantas (Galán Saúco \& Menini, 1989). Dessa forma, o objetivo deste trabalho foi avaliar a diversidade genética, com base em características físicas e químicas, de frutos de 15 cultivares de mangueiras produzidos na Zona da Mata Mineira

\section{MATERIAL E MÉTODOS}

O estudo foi desenvolvido durante a safra 2007/08, em pomar com cerca de 30 anos de idade, em espaçamento 8 x 8, com 15 cultivares de mangueira (Tabela 1 ), do pomar experimental da Universidade Federal de Viçosa

Tabela 1. Cultivares de mangueira utilizados e sua origem

\begin{tabular}{lc}
\hline Cultivares brasileiros & Cultivares americanos \\
\hline 'Amarelinha' & 'Edward' \\
'Espada' & 'Irwin' \\
'Extrema' & 'Haden' \\
'Felipe' & 'Kent' \\
'Oliveira Neto' & 'Palmer' \\
'Soares Gouveia' & 'Tommy Atkins' \\
'Taú' & 'Zill' \\
'Ubá' & \\
\hline
\end{tabular}


(UFV), Viçosa, Minas Gerais (MG) (latitude 2045’20"S e longitude $42^{\circ} 52^{\prime} 40^{\prime \prime O}$, altitude de 649m) e na Fazenda Experimental da UFV, em Visconde do Rio Branco, MG (latitude de $21^{\circ} 00^{\prime} 37^{\prime \prime S}$, longitude de 4250’26"O, altitude de $352 \mathrm{~m})$.

Os frutos foram colhidos manualmente, no estádio de maturação completa. Os critérios utilizados para determinar o ponto de colheita foram a cor da casca e o enchimento do ombro em relação ao pedúnculo (Genú \& Pinto, 2002), e apresentavam polpa macia, cor amarela ou vermelha da casca e laranja da polpa, desenvolvimento do aroma e sabor característicos para cada cultivar (Silva et al., 2009). Foram coletadas três repetições e cinco frutos por parcela, sendo colhido, para cada cultivar, três frutos em cada planta, totalizando cinco plantas por variedade e 15 frutos por cultivar, para posteriores análises em laboratório.

Após a colheita, os frutos foram transportados para o Laboratório de Análises de Frutas da UFV, onde foram lavados, secos ao ar e submetidos a análises físicas e químicas. A coloração da polpa dos frutos, no momento da colheita, era amarelada na região central do fruto próxima à semente, o que pode ser observado pelo ângulo hue da polpa.

As características físicas avaliadas foram: massa dos frutos $(\mathrm{g})$, proporção de sementes, de casca e de polpa dos frutos, firmeza da polpa, coloração da casca e da polpa.

A massa dos frutos foi avaliada por gravimetria, em balança eletrônica de precisão de $0,1 \mathrm{~g}$. Após a determinação, os frutos foram descascados e despolpados, em seguida, as cascas e as sementes foram pesadas. A massa da polpa foi determinada por subtração (massa dos frutos - massa das cascas - massa das sementes). O cálculo das proporções de polpa, de casca e de semente foi feito em relação à massa dos frutos.

A firmeza da polpa foi avaliada por meio de penetrômetro tipo SHIMPO DFS 100 com ponteira ( 12 mm de diâmetro) e os resultados foram expressos em Newton (N).

A coloração da casca e da polpa foi avaliada mediante duas leituras, efetuadas em lados opostos da casca, na região equatorial dos frutos, e uma leitura interna, na região central da polpa. As leituras foram realizadas empregando-se um colorímetro Minolta CR-300. No padrão C.I.E. L*a*b*, a coordenada $\mathrm{L}^{*}$ expressa o grau de luminosidade da cor medida $\left(\mathrm{L}^{*}=100=\right.$ branco; $\mathrm{L}^{*}=0=$ preto). A coordenada $a^{*}$ expressa o grau de variação entre o vermelho e o verde $\left(a^{*}\right.$ mais negativo $=$ mais verde; $\mathrm{a}^{*}$ mais positivo = mais vermelho) e a coordenada $b^{*}$ expressa o grau de variação entre o azul e o amarelo $\left(b^{*}\right.$ mais negativo $=$ mais azul; $b^{*}$ mais positivo $=$ mais amarelo) e ângulo Hue de cor $\left({ }^{\circ} \mathrm{h}\right)$, que indica $0^{\circ}=$ vermelho; $90^{\circ}=$ amarelo $; 180^{\circ}=$ verde $; 270^{\circ}=$ azul (Minolta Corp, 1994).
As características químicas avaliadas da polpa foram a acidez titulável (AT), os sólidos solúveis (SS), a relação SS/AT, os teores de vitamina $\mathrm{C}$, de carotenoides, de açúcares solúveis totais e de amido.

A AT foi determinada por titulometria com solução de $\mathrm{NaOH} 0,1 \mathrm{~N}$ e indicador fenolftaleína e os resultados foram expressos em $\mathrm{g}$ de ácido cítrico por $100 \mathrm{~g}$ de polpa. Os SS foram determinados com o uso de refratômetro digital e expressos em ${ }^{\circ}$ Brix. $\mathrm{O}$ teor de vitamina $\mathrm{C}$ foi determinado por titulação com reagente de Tillman [2,6 diclorofenolindofenol (sal sódico) a 0,1\%], de acordo com metodologia descrita em AOAC (1997), sendo os resultados expressos em $\mathrm{mg} / 100 \mathrm{~g}$.

Para avaliação dos carotenoides, foram pesados aproximadamente $2,0 \mathrm{~g}$ de polpa, a qual foi triturada em cadinho com areia lavada, acetona a $80 \%$ e $0,5 \mathrm{~g} \mathrm{de} \mathrm{CaCO}_{3}$. O extrato cetônico foi filtrado em papel de filtro e o volume completado para $25 \mathrm{~mL}$. As absorbâncias foram determinadas a 470, 646,8 e 663,2 nm, sendo os teores de carotenoides determinados, segundo as equações de Lichtenthaler (1987), em $\mu \mathrm{g} / \mathrm{mL}$ de extrato. Os açúcares solúveis totais foram extraídos em etanol e o amido foi quantificado a partir do resíduo remanescente das extrações etanólicas, mediante a metodologia descrita por McCready et al. (1950), modificada por Patel (1970), sendo os resultados expressos em \% de polpa fresca.

As médias dos dados obtidos de cada característica avaliada para os diferentes cultivares de mangueira foram analisadas e comparadas. Para isto, fez-se o estudo da dissimilaridade genética, utilizando-se a Distância Euclidiana Média. A partir da matriz de dissimilaridade gerada, procedeu-se à análise de agrupamento pelos métodos UPGMA (Unweighted pair group method with arithimetical averages) e Tocher. A matriz de dissimilaridade foi usada para a construção do dendrograma, de acordo com o Método de Agrupamento não Ponderado, com base na Média Aritmética - UPGMA (Sneath \& Sokal, 1973). Para o dendrograma gerado, foi calculado o coeficiente de correlação cofenética (r). Além disso, efetuou-se a análise de componentes principais, a fim de obter-se a dispersão gráfica em espaço bidimensional dos genótipos estudados, e de correlação de Pearson. Todos os procedimentos estatísticos utilizaram o programa GENES (Cruz, 2006; 2008).

\section{RESULTADOS E DISCUSSÃO}

Com base na matriz de dissimilaridade obteve-se que as mangueiras 'Kent' e 'Palmer' são as mais próximas ( $\mathrm{d}=$ $0,64)$, isto é, apresentaram menor dissimilaridade, e as mais distantes $(\mathrm{d}=2,30)$ são a 'Tommy Atkins' e a 'Extrema' (Tabela 2). A menor dissimilaridade apresentada pelas mangueiras 'Kent' e 'Palmer' pode, em parte, ser explicada pelo fato de elas terem um genitor em comum, o cultivar 'Haden' (Santos et al., 2008). 


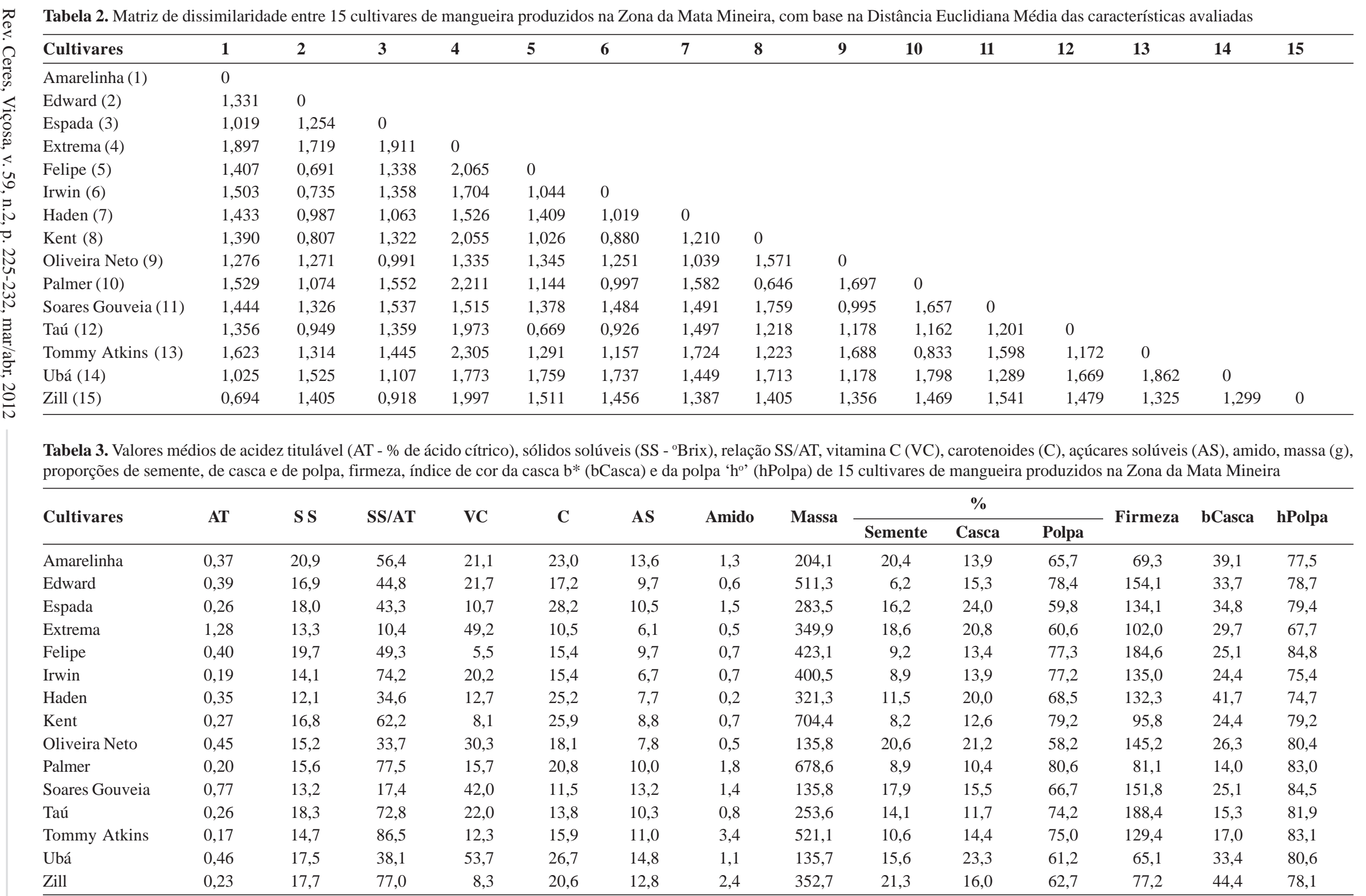




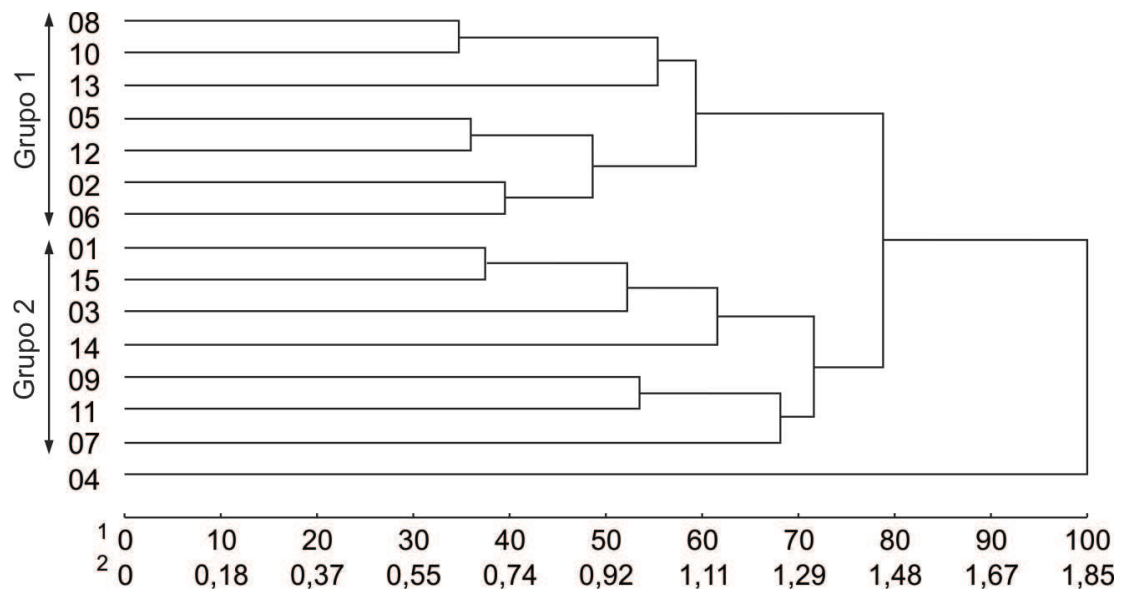

Figura 1. Dendrograma, para 15 cultivares de mangueira produzidos na Zona da Mata Mineira, gerado pelo método de agrupamento UPGMA, utilizando a matriz de dissimilaridade com base na Distância Euclidiana Média. 01 - 'Amarelinha', 02 - 'Edward', 03 - 'Espada', 04 - 'Extrema', 05 - 'Felipe', 06 - 'Irwin', 07 - 'Haden', 08 - 'Kent', 09 - 'Oliveira Neto', 10 - 'Palmer', 11 - 'Soares Gouveia', 12 - 'Taú', 13 - 'Tommy Atkins', 14 - 'Ubá', 15 - 'Zill'. 'Escala das distâncias em percentagem em relação ao último ponto de fusão e ${ }^{2}$ distância em valores reais.

Observa-se, no dendrograma (Figura 1), que os cultivares se juntaram em dois grupos, sendo que, no grupo 1, ficaram alocados os cultivares 'Edward', 'Irwin', 'Kent', 'Palmer' e 'Tommy Atkins', estes oriundos dos Estados Unidos, juntamente com 'Felipe' e 'Taú'. Santos et al. (2008), estudando a similaridade de 105 acessos de manga com marcadores AFLP, observaram que o cultivar 'Palmer' ficou separado dos cultivares do grupo em que aparece neste trabalho. No grupo 2, têm-se, basicamente, cultivares brasileiros, ou seja, 'Amarelinha', 'Espada', 'Oliveira Neto', 'Soares Gouveia' e 'Ubá', além dos cultivares 'Zill' e 'Haden' dos Estados Unidos. Já o cultivar brasileiro 'Extrema' não se agrupou com os demais.

Dos 15 cultivares avaliados no presente trabalho, oito são provenientes do Brasil e, destes, cinco foram agrupados no segundo grupo. Segundo Pinto et al. (2004), os cultivares brasileiros são resultantes das introduções, efetuadas pelos portugueses, no século XVI, de genótipos filipínicos, geralmente, fibrosos e poliembriônicos.

A separação destes dois grupos foi dada pela percentagem de polpa, sendo que os cultivares do grupo 1 apresentaram as maiores proporções de polpa, tanto em relação aos cultivares do grupo 2, quanto ao cultivar 'Extrema' (Tabela 3), que apresentou menor relação SS/AT, menores teores de carotenoides e açúcares, assim como polpa mais alaranjada (Tabela 3).

Dos cultivares que compõem o grupo 1, 'Irwin', 'Felipe' e 'Taú' não têm origem conhecida; os demais tem o 'Haden' como um dos genitores. O cultivar 'Zill' também tem 'Haden' como um dos genitores; estes, porém, se alocaram no subgrupo 2. O fato de 'Haden' ter ficado separado de alguns de seus filhos pode ter ocorrido por estar-se analisando caracteres fenotípicos e a separação dos dois subgrupos ter sido dada pelo rendimento de polpa (Tabela 3). Esta característica quantitativa pode ser controlada por mais de um gene e, com isto, um filho pode não responder igualmente ao genitor.

Todos os cultivares estudados apresentaram similaridade superior a 20\% (Figura 1), o que evidencia sua alta variabilidade genética. Schnell et al. (1995), analisando 25 acessos de cultivares majoritariamente Floridiana (EUA), encontraram similaridade superior a $64 \%$, enquanto Viruel et al. (2005) observaram similaridade superior a 33\% em 28 acessos de mangueira de diversas origens, o que também evidencia a alta variabilidade genética da mangueira.

A análise de componentes principais para as características químicas, acidez titulável, vitamina $\mathrm{C}$, carotenoides, açúcares solúveis totais, amido, sólidos solúveis e relação SS/AT mostrou que a variação existente entre os cultivares é explicada, em 83,5\%, por três componentes principais. O componente 1 explica $45,73 \%$, o 2, 20,88\%, e, o 3,16,89\%, tendo como variáveis de maior peso a acidez titulável e os teores de açúcar e de amido, respectivamente. Pela Figura 2, observa-se que, para os componentes principais 1 e 3, os cultivares 'Extrema' e ‘Tommy Atkins' ficaram separados dos demais. Já o componente principal 2 não mostrou separação clara entre os cultivares.

A variação existente entre as características físicas massa de frutos, proporção de casca, de semente e de polpa, firmeza da polpa, índice $\mathrm{b}^{*}$ da cor da casa e $\mathrm{h}^{\circ} \mathrm{da}$ polpa é $84,61 \%$ explicada por três componentes principais. O primeiro componente principal explica 53,27\% e nele a variável de maior peso é a percentagem de polpa. $\mathrm{O}$ segundo componente explica, $19,89 \%$ e, o terceiro, $11,45 \%$, e a variável de maior peso para o segundo e terceiro componentes é a firmeza da polpa. Observa-se, na Figura 3, que houve a separação dos cultivares em dois grupos (A e B) e isto se deu pelo primeiro componente principal. 
Estes grupos formados são os mesmos gerados pelo agrupamento UPGMA, porém, neste caso o cultivar 'Extrema' não se separou dos demais cultivares.

A variável química de maior peso foi a acidez titulável, explicando 45,73\% da variação existente entre os cultivares, e a variável física de maior peso foi a proporção de polpa, que explica 53,27\% da variação. Estes resultados são de extrema importância para o programa de melhoramento em andamento.

A acidez titulável apresentou correlação direta com o teor de vitamina $\mathrm{C}$ e inversa com a relação SS/AT (Tabela 4), o que é esperado. A vitamina C ou ácido ascórbico, que, como os outros ácidos presentes em mangas, diminui com o amadurecimento (Cardello \& Cardello, 1998),

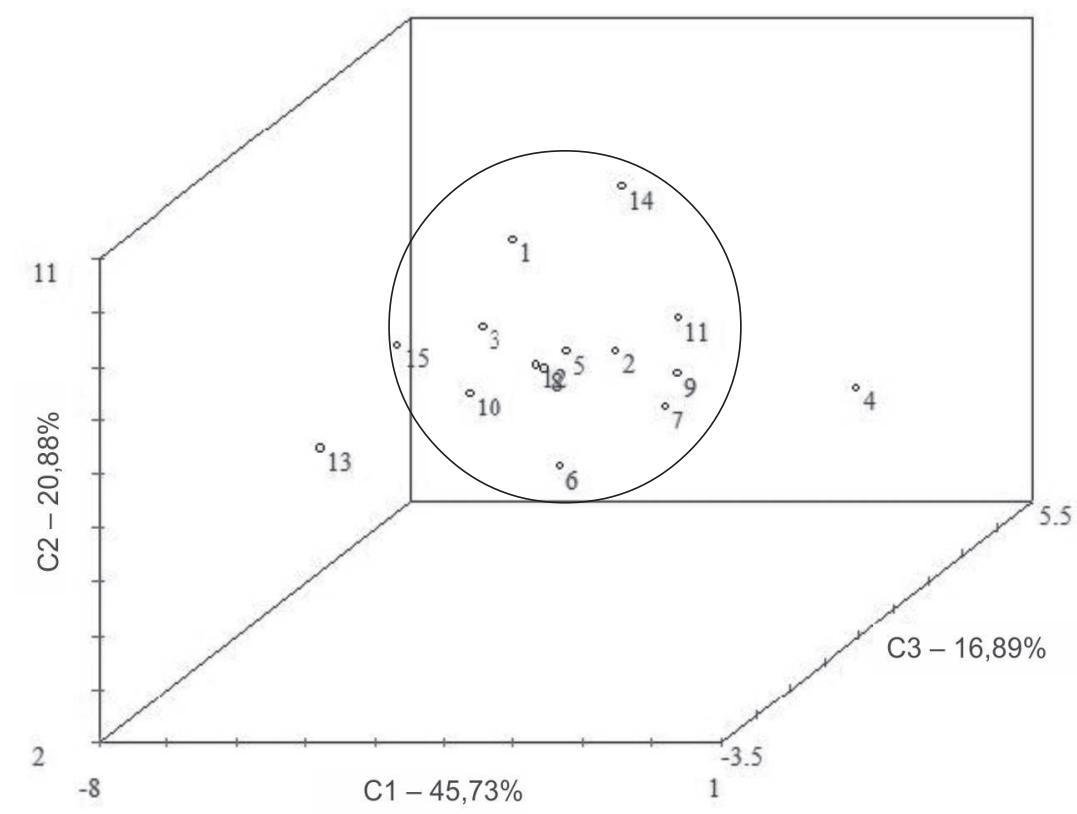

Figura 2. Dispersão gráfica de 15 cultivares de mangueiras cultivados na Zona da Mata Mineira, obtida pela análise de componentes principais, para as características químicas, acidez titulável, sólidos solúveis, relação SS/AT, vitamina C, carotenoides, açúcares solúveis totais e amido. 01 - 'Amarelinha', 02 - 'Edward', 03 - 'Espada', 04 - 'Extrema', 05 - 'Felipe', 06 - 'Irwin', 07 - 'Haden', 08 - 'Kent', 09 - 'Oliveira Neto', 10 - 'Palmer', 11 - 'Soares Gouveia', 12 - 'Taú', 13 - 'Tommy Atkins', 14 - 'Ubá', 15 - 'Zill'.

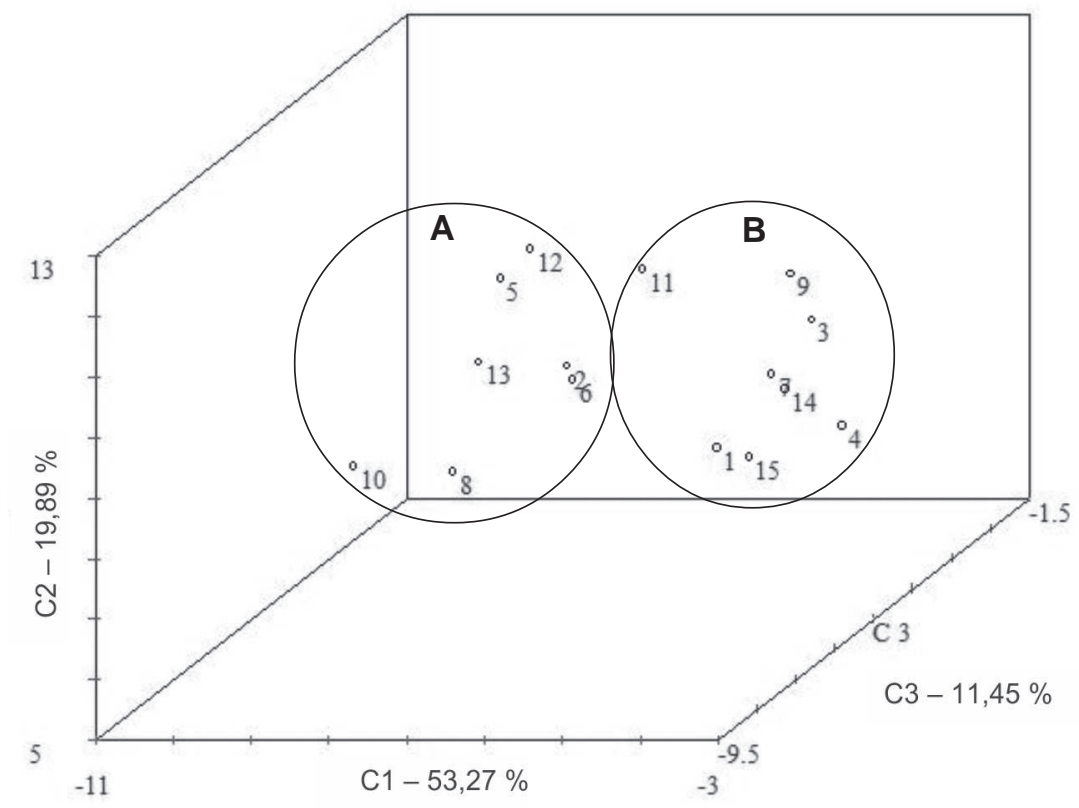

Figura 3. Dispersão gráfica de 15 cultivares de mangueiras cultivados na Zona da Mata Mineira, obtida pela análise de componentes principais, para as características físicas (massa de frutos, percentagem de semente, de casca e de polpa, firmeza, coloração da casca e da polpa pelos índices b* e h', respectivamente). 1 - 'Amarelinha', 2 - 'Edward', 3 - 'Espada', 4 - 'Extrema', 5 - 'Felipe', 6 - 'Irwin', 7 'Haden', 8 - 'Kent', 9 - 'Oliveira Neto', 10 - 'Palmer', 11 - 'Soares Gouveia', 12 - 'Taú', 13 - 'Tommy Atkins', 14 - 'Ubá', 15 - 'Zill'. 


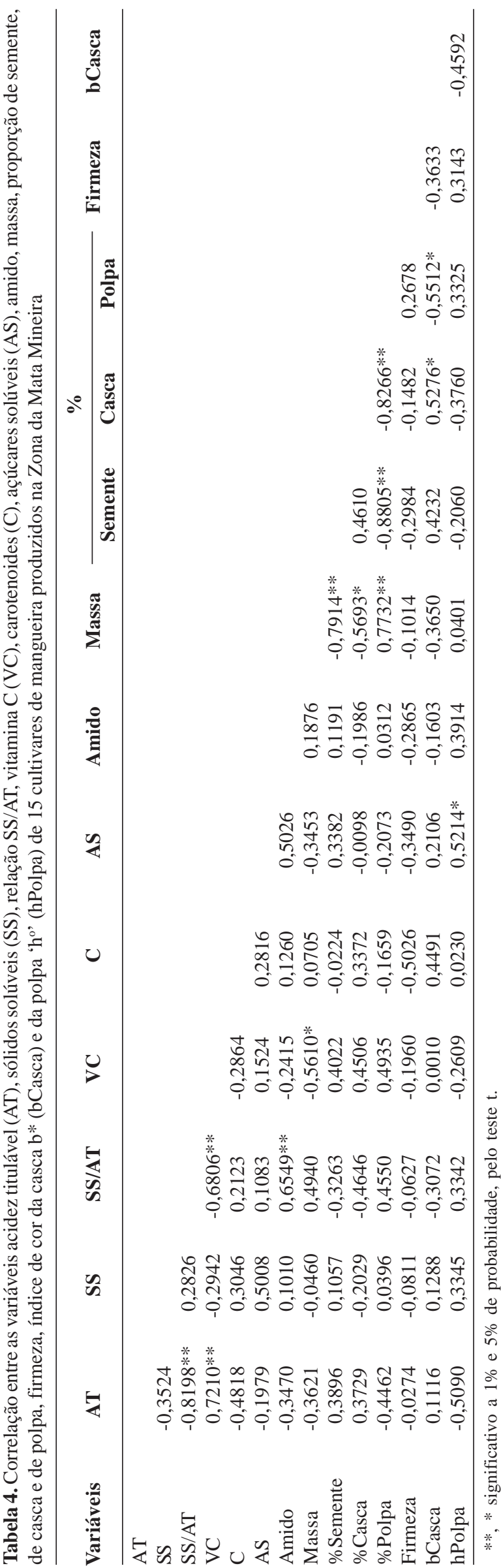

apresentou correlação direta, isto é, quanto maior o teor da acidez titulável maior o teor de vitamina $\mathrm{C}$.

A variável relação SS/AT apresentou correlação negativa com vitamina $\mathrm{C}$ o que é explicado pelo fato de a vitamina $\mathrm{C}$ ser um ácido e de a relação SS/AT ter relação inversa com acidez. Além disto, a relação SS/AT apresentou correlação positiva com amido (Tabela 3). A vitamina $\mathrm{C}$ apresentou correlação negativa com a massa dos frutos, isto é, quanto mais massa tem o fruto, menor o teor de vitamina C. O teor de açúcar apresentou correlação positiva com o ângulo hue $\left(\mathrm{h}^{\circ}\right)$ da polpa, isto é, quanto maior $\mathrm{h}^{\circ}$, maior será o teor de açúcar; portanto, frutos com coloração de polpa tendendo ao amarelo-claro são mais doces. A massa dos frutos apresentou correlação positiva com a percentagem de polpa, de semente e de casca, pois estas são função da massa dos frutos.

A proporção de polpa apresentou correlação negativa com a proporção de semente e de casca e com o índice b* de cor da casca. A correlação negativa com a proporção de casca e de semente pode ser explicada por haver competição entre elas. Isto mostra que quanto mais polpa, menos casca e semente. O índice $b^{*}$ para cor da casca apresentou correlação positiva com a percentagem de casca e negativa com proporção de polpa, o que indica que frutos com cascas amareladas apresentam menor proporção de polpa e maior, de casca.

\section{CONCLUSÕES}

Os 15 cultivares analisados apresentam variabilidade quanto às características químicas e físicas dos frutos. Os cultivares que apresentam maior similaridade são 'Kent' e 'Palmer' e os mais distantes 'Extrema' e 'Tommy Atkins'.

Os cultivares 'Haden' e 'Zill', de origem da Flórida, apresentam características físicas (proporção de polpa e de massa dos frutos) mais próximas dos cultivares brasileiros do que dos demais cultivares oriundos da Flórida. E estas características os separam.

\section{AGRADECIMENTOS}

ACAPES, CNPq e FAPEMIG pelo apoio financeiro.

\section{REFERÊNCIAS}

Amorim EP, Ramos NP, Ungaro MRG \& Kiihl TAM (2007) Divergência genética em genótipos de girassol. Ciência e Agrotecnologia, 31:1637-1644.

AOAC (1997) Official methods of analysis of the Association of Official Analytical Chemists International. 16 ${ }^{\text {th }}$ ed. Washington, AOAC, 2:37-10, 42-2, 44-3, 45-16.

Cardello HMAB \& Cardello L (1998) Teor de vitamina C, atividade de ascorbato oxidase e perfil sensorial de manga (Mangifera indica L.) var. Haden, durante o amadurecimento. Ciência e Tecnologia de Alimentos, 18:211-217. 
Chahidi B, El-otmani M, Jacquemond C, Tijane M. El-mousadik A, Srairi I \& Luro F (2008) Utilisation de caracteres morphologiques, physiologiques et de marqueurs moléculaires pour l'évaluation de la diversité génétique de trois cultivars de clémentinier. Comptes Rendus Biologies, 331:1-12.

Cruz CD (2006) Programa GENES - Análise multivariada e simulação. Viçosa, UFV, 175p.

Cruz CD (2008) Programa GENES - Diversidade genética. Viçosa, UFV, 278p.

Galán Saúco V \& Menini UG (1989) Litchi cultivation. Roma, FAO Plant Production and Protection. 136p. (Paper, 83)

Galli JA, Michelotto MD, Silveira LCP \& Martins ALM (2008) Qualidade de mangas cultivadas no Estado de São Paulo. Bragantia, 67:791-797.

Genú PJC \& Pinto ACQ (2002) A cultura da mangueira. Brasília, Embrapa Informação Tecnológica. 454p.

Lichtenthaler HK (1987) Chlorophylls and carotenoids: Pigments of photosynthetic biomembranes. Methods in Enzymology, 148:349-381

McCready RM, Guggolz J, Silveira V \& Owens HS (1950) Determination of starch and amylose in vegetables. Aplication to peas. Analytical Chemistry, 22:1156-1158.

Minolta Corp (1994) Precise color communication: color control from feeling to instrumentation. Ramsey, Minolta Corporation Instrument Systems Division. 49p.

Morales RGF, Resende JTV de, Faria MV, Silva PR da, Figueiredo AST \& Carminatti R (2011). Divergência genética em cultivares de morangueiro, baseada em caracteres morfoagronômicos. Revista Ceres, 58:323-329

Moura WM, Casali VWD \& Cruz CD (1999) Divergência genética em linhagens de pimentão em relação a eficiência nutricional de fósforo. Pesquisa Agropecuária Brasileira, 34:217-224.
Pandit SS, Mitra S, Giri AP, Pujar KH, Patil BP, Jambhale ND \& Gupta VS (2007) Genetic diversity analysis of mango cultivars using inter simple sequence repeat markers. Current Science, 93:1135-1141.

Patel RZ (1970) A note on the seasonal variations in starch content of different parts of coffea arabica trees. East African Agricultural and Forestry Journal, 36:1-6.

Pinto ACQ, Andrade SRM, Amaro AA \& Gomes U (2004) Mango industry in Brazil. Acta Horticulturae, 645:37-50.

Rodrigues HC de A, Carvalho SP de, Carvalho AA de, Filho JLS de C \& Custódio TN (2010) Avaliação da diversidade genética entre acessos de mamoneira (Ricinus communis L.) por meio de caracteres morfoagronômicos. Revista Ceres, 57:773-777.

Santos CAF, Neto FPL, Rodrigues MA \& Costa JG (2008) Similaridade genética de acessos de mangueira de diferentes origens geográficas avaliadas por marcadores AFLP. Revista Brasileira de Fruticultura, 30:736-740.

Schnell JR, Ronning CM \& Knight RJ (1995) Identification of cultivars and validation of genetic relationships in Mangifera indica L. using RAPD markers. Theoretical Applied Genetic, 90:269-274

Silva DFP, Siqueira DL, Pereira CS, Salomão LCC \& Struiving TB (2009). Caracterização de frutos de 15 cultivares de mangueira na Zona da Mata Mineira. Revista Ceres, 56:783-789.

Sneath PH \& Sokal RR (1973) Numerical taxonomy: The principles and practice of numerical classification. San Francisco, W.H. Freeman. 573p.

Viruel MA, Escribano P, Barbieri M, Ferri M \& Hormaza JI (2005) Fingerprinting, embryo type and geographic differentiation in mango (Mangifera indica L., Anacardiaceae) with microsatélites. Molecular Breeding, 15:383-393. 